\title{
Animal Behaviour \\ Objective and subjective components of resource value in lethal fights between male entomopathogenic nematodes \\ --Manuscript Draft--
}

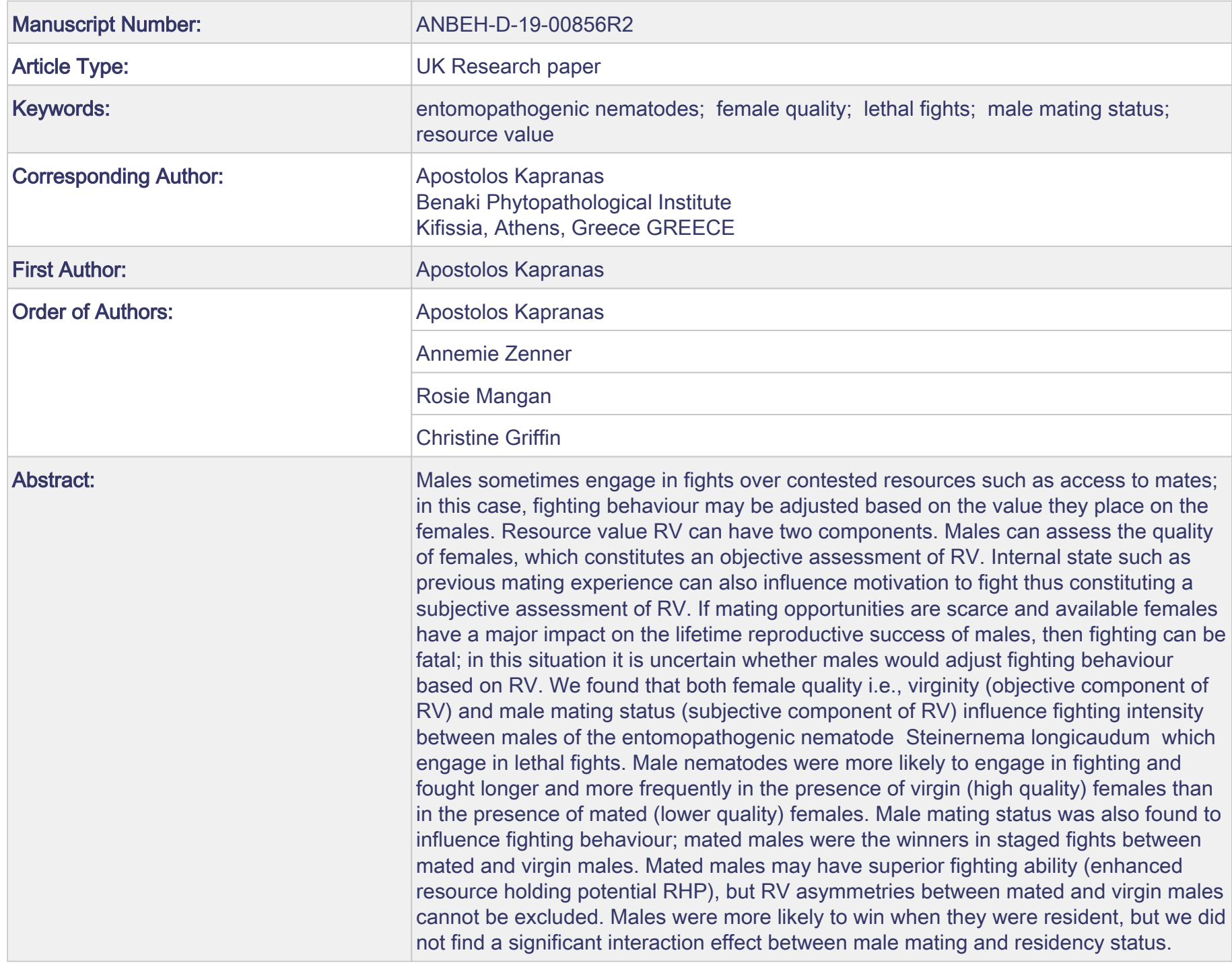

Accepted refereed manuscript of: Kapranas A, Zenner ANRL, Mangan R \& Griffin CT (2020) Objective and subjective components of resource in lethal fights between male entomopathogenic nematodes. Animal Behaviour, 164, pp. 149 - 154.https://doi.org/10.1016/j.anbehav.2020.04.015

(c) 2020. Elsevier. Licensed under the Creative Commons Attribution-NonCommercial-NoDerivatives 4.0 International http://creativecommons.org/licenses/by -nc-nd/4.0/ 


\title{
Objective and subjective components of resource value in lethal fights between male entomopathogenic nematodes
}

\author{
Apostolos Kapranas $^{1 *}$, Annemie N. R. L.Zenner ${ }^{2}$, Rosie Mangan ${ }^{3}$, Christine T. Griffin ${ }^{2}$
}

Running title: female quality and male mating status influence fighting behaviour in male nematodes

${ }^{1}$ Benaki Phytopathological Institute, Kifissia, Attica, GR-145 61, Greece

${ }^{2}$ Department of Biology, Maynooth University, Maynooth, County Kildare, Ireland

${ }^{3}$ Biological and Environmental Sciences, Faculty of Natural Sciences, University of Stirling, Stirling, FK9 4LA, Scotland, UK

*Corresponding author:

Benaki Phytopathological Institute, 8 St. Delta str., GR-145 61 Kifissia, Attica, Greece Tel.: +30 2108180216 •email: a.kapranas@bpi.gr

\section{ACKNOWLEDGEMENTS}

We thank Ms Aideen Byrne for technical assistance. All experimentation reported in this work abides to the principles of replacement, reduction and refinement as endorsed by the Association for the Study of Animal Behaviour (ASAB).

\section{FUNDING}

This work was supported by Science Foundation Ireland (Grant number RFP05/EEB0009) and the EU Seventh Framework Programme (grant agreement nº 612713 BIOCOMES Project). 


\section{Objective and subjective components of resource value in lethal fights between male entomopathogenic nematodes}

\section{ABSTRACT}

Males sometimes engage in fights over contested resources such as access to mates; in this case, fighting behaviour may be adjusted based on the value they place on the females.

Resource value RV can have two components. Males can assess the quality of females, which constitutes an objective assessment of RV. Internal state such as previous mating experience can also influence motivation to fight thus constituting a subjective assessment of RV. If mating opportunities are scarce and available females have a major impact on the lifetime reproductive success of males, then fighting can be fatal; in this situation it is uncertain whether males would adjust fighting behaviour based on RV. We found that both female quality i.e., virginity (objective component of RV) and male mating status (subjective component of RV) influence fighting intensity between males of the entomopathogenic nematode Steinernema longicaudum which engage in lethal fights. Male nematodes were more likely to engage in fighting and fought longer and more frequently in the presence of virgin (high quality) females than in the presence of mated (lower quality) females. Male mating status was also found to influence fighting behaviour; mated males were the winners in staged fights between mated and virgin males. Mated males may have superior fighting ability (enhanced resource holding potential RHP), but RV asymmetries between mated and virgin males cannot be excluded. Males were more likely to win when they were resident, but we did not find a significant interaction effect between male mating and residency status. Key words: entomopathogenic nematodes, female quality, lethal fights, male mating status, resource value. 


\section{INTRODUCTION}

Animals frequently engage in contests over resources that impact their fitness, such as mates, territories or nesting sites (Andersson 1994). Amongst the most important factors influencing the extent and outcome of contest behaviour are the resource holding potential of the contestants, the value of the resource and the costs of fighting (Parker 1974; Arnott \& Elwood 2008; Hardy \& Briffa 2013). Resource holding potential RHP (fighting ability) of the contestants may depend on their weaponry, energy reserves and body size (Parker 1974; Arnott \& Elwood 2009; Hardy \& Briffa 2013; Rico-Guevara \& Hurme 2019). Resource value RV has two components: objective and subjective; Intrinsic properties of the resource that will yield a certain fitness gain to a successful competitor constitute the objective components of resource value, while the value of a given resource may vary for each contestant depending on its own internal state and prior experience (subjective component of resource value) (Enquist \& Leimar 1987; Arnott \& Elwood 2008). These components of resource value may simultaneously influence the ultimate value of the resource (Stockermans \& Hardy 2013).

Objective and subjective components of resource value have been widely studied in contests between males for mates, where the contested resource is receptive females. When females are scarce, males may be more motivated to fight, but this motivation can also depend on female quality which can be based on size (larger females are more fecund), nearness to moult or mating status (Crespi 1988; Dick \& Elwood 1990; Arnott \& Elwood 2008; Keil \& Watson 2010; Hoefler et al. 2009; Ancona et al. 2010; Kasumovic et al. 2011). Furthermore, males' internal state, such as their own mating status, can influence subjectively the value that they place on the contested resource (i.e., mates) (Arnott \& Elwood 2008). Mated males may become less aggressive and more likely to lose at contests due to the energetic cost of mating (Brown et al. 2006, 2007; Judge et al. 2010). On the other hand, previous mating experience has been shown to increase a male's aggression and fighting success in several animal taxa 
because of changes in the male's self-assessment of RHP and perception of the resource value, that are similar to winner/loser effects (Killian and Allen 2008; Yasuda et al. 2015, Dugatkin \& Dugatkin 2011; Zhang et al., 2019). If an animal wins a contest then its perception of fighting ability increases and it is more likely to initiate future fights and win them, whereas losers lower their RHP perception, are less aggressive and more likely to lose (Hsu et al. 2006). Mating status is also related to the residual reproductive value (number of future offspring) which is predicted to influence male investment in fighting (Kemp 2006). An unmated male can be more aggressive and more motivated to fight because future mating opportunities are of greater value to him, whereas a mated male may be less willing to engage in costly fighting (Kemp 2006).

Fighting is costly, risking injury and using time and energy that could be used in mating or other activities (Maynard Smith \& Price 1973; Briffa \& Sneddon 2007). As the value of the contested resource increases, the cost of fighting can also increase (Enquist \& Leimar 1987; Kokko 2013). If the contested resource has a major impact on the lifetime reproductive success of the the contenstants, such as limited females, then fights can escalate to serious injury and even death (Enquist \& Leimar 1987, 1990; Maynard Smith \& Parker 1976). Lethal male fighting has been recorded in some vertebrates (e.g., Piper et al. 2008) and numerous arthropods, particularly arachnids (DeCarvalho et al. 2004; Sato et al. 2013) and hymenopterans (Anderson et al. 2003; Matthews et al. 2009; Cook \& Bean 2006; Hamilton 1979; Innocent et al. 2007; Innocent et al. 2011) and lately in entomopathogenic nematodes (Zenner et al. 2014; Kapranas et al. 2016). Whereas contested resource availability, such as potential mates, is critical in prompting lethal fights (Enquist \& Leimar 1990), it is unclear to what extent the contestants also assess the quality of resource in such species. When mating opportunities for males are extremely limited then their motivation to fight would be expected to be independent of resource quality even if the odds of dying in a fight are high (Enquist \& 
Leimar 1990). Amongst parasitoid hymenopterans with lethal male combat, some species adjust fighting behaviour according to the value of the resource (Liu \& Hao 2019), while others do not (Innocent et al. 2011).

Here we investigate the effect of objective and subjective resource value on lethal contests of male entomopathogenic nematodes Steinernema longicaudum Shen and Wang.

We are able to manipulate the mating status of the contestant males and also the quality of the contested resource by staging dyadic contests in a controlled environment (drops of haemolymph of their insect host). First, we assess how the presence/absence and quality of available females (objective components of resource value) influence fighting behaviour between mated males. We predict that the presence of a female, especially a virgin, will increase the frequency and/or severity of fighting in S. longicaudum. Then, we assess whether male mating status (subjective components of resource value) influences the contest outcome. We do not have a directional prediction of how mating influences fighting, but we hypothesize that either mated or virgin males will have a consistent advantage over the other, and this will provide insights regarding how male nematodes assess the value of their mates and whether mating status influences fighting ability.

\section{MATERIALS AND METHODS}

\section{Nematode Reproductive Biology and Lethal Fighting.}

Infection by entomopathogenic nematodes including $S$. longicaudum begins when freeforaging infective juveniles (IJs) enter an insect host and release their symbiotic bacteria that turn the host insect into a cadaver. In S. longicaudum, IJs develop into amphimictic males and females, with a sex ratio that is slightly female biased (Alsaiyah et al. 2009). Two or more generations develop until the cadaver is crowded, prompting the production of IJs that exit in 
search of other hosts (Kaya \& Gaugler 1993; Dillman \& Sternberg 2012). In S. longicaudum it was shown that males are aggressive towards each other and engage in lethal fights (Zenner et al. 2014). During male-male encounters, an aggressor coils its tail end around a victim, with the copulatory spicules towards the victim's body. If not gripped close to the tail, the victim may counter-attack, wrapping its tail around the aggressor. Grappling encounters frequently end when the grasped male ceases to move part or all of its body, which may happen within minutes (Zenner et al. 2014). Such worms usually die, though partially paralyzed worms occasionally recover movement. The cuticle is sometimes punctured, but paralysis and death occur also without puncture, apparently due to damage to internal organs.

\section{Nematode Cultures and Behavioural Assays}

Steinernema longicaudum (strain CB2B) cultures were routinely maintained using standard procedures by passage through late instar Galleria mellonella (wax moth) larvae (Kaya \& Stock 1997) at $27^{\circ} \mathrm{C}$. Infective juveniles were stored in tap water at $20^{\circ} \mathrm{C}$. We obtained adult males for our experiments by placing IJs individually in $25 \mu 1$ hanging drops of haemolymph from G. mellonella larvae which provides a suitable environment for development to adulthood (Kaya \& Stock 1997; Zenner et al. 2014). The hanging drops were placed on the lid of a Petri dish which was then inverted over a water-filled Petri dish $(6 \mathrm{~cm} \mathrm{diam}$.) to prevent desiccation. The IJs in the hanging drops develop to adulthood within 3 days at $27^{\circ} \mathrm{C}$. Adult males can be distinguished by their copulatory spicules and their smaller size whereas females are larger in size and bear vulva. We used three days old males and females in our experiments.

\section{Experiment 1: Effects of Female Mating Status}


All males used in this experiment were mated. We placed each individual naïve male for 1620 hours with 2 naïve females to mate. We then removed the females, and successful mating was subsequently confirmed by the production of progeny. We removed two adult males from their hanging drops and placed them immediately, in pairs, back in the drop from which one member of the pair had been taken. Thus, one worm was "resident" and one an "intruder", but the identity of each was not tracked, as there were no clear visual differences between them. Worms were assigned to the following treatments: (i) 2 mated males with a mated female $(N$ =34); (ii) 2 mated males with a virgin female (same age as mated female) $(N=31)$; (iii) 2 mated males without a female $(N=35)$. A mating attempt was recorded when a male coiled around the female at the vulva; insertion of spicules into the vulva was difficult to observe due to the coiling of the male around the female. A fight was recorded once one male coiled tightly around another and then let go. Continuous observations were made for 30 mins during which the latency to first fight, the incidence (whether at least one fighting event occurred), number and (for a subsample) duration of fights were recorded. Paralysis and/or death of the males was recorded at the end of the observation and after 24 hours.

\section{Experiment 2: Effects of Male Mating Status}

In S. longicaudum, males that have been with a female can be distinguished from those that have not, based on the presence of sperm in the seminal vesicle, visible through the body wall (Ebssa et al., 2008); thus, mating status of individual males in a pair could be recognized. In this experiment, we placed together an adult male that had mated and a virgin one. Mated males were obtained by placing two females in the drop of an individually reared adult male for 24 hours, after which the females were removed to a different drop and observed for later progeny production. We set up pairs of one mated and one virgin adult male either in the drop in which the mated male had been reared and mated $(N=21)$ or in the drop in which the 
unmated male had been reared $(N=24)$. In this case, since mated and unmated males differed in appearance, the identity of "resident" and "intruder" could also be traced. After 24 hours we observed which worms showed signs of paralysis or death. Individual males were identified as the mated or virgin member of the pair by examining for the presence of sperm using a Nikon Optiphot microscope (x40).

\section{Statistics}

Analysis of factors influencing the number of fights, as well copulations observed in our assays and the probability of paralysis/death were explored with generalized linear models as described in Briffa et al. (2013). To test the hypothesis that objective resource value affects fighting behavior, we used a log-linear analysis which is appropriate for small count data, to assess how female presence and mating status (predictor variables) affected the number of fights (dependent variable). Post-hoc tests among different treatments whenever applicable were adjusted with the Bonferroni correction. The probability of paralysis and/or death at the end of the 30 min observation period and $24 \mathrm{~h}$ post observations was explored with logistic analysis. Duration of fighting in different treatments (no females, mated and virgin females) was analysed with a non-parametric Kruskal Wallis test and latency to fighting was analysed using survival regression analysis (Moya-Larano \& Wise 2000). In the second experiment, we compared the incidence of paralysis/death in contests staged in drops where the resident male was mated versus drops where the resident was a virgin male, by using a Fisher's exact test. For those pairs in which paralysis or death occurred, we used a logistic analysis by randomly picking a focal male (either mated or virgin) in each replicate and tested the effect of residency and mating status (as factors) and their interaction on the probability of the focal male winning the contest (Briffa et al. 2013). All analysis was performed in SPSS v.21 (IBM, Armonk, NY, USA). 
RESULTS

177

Female Presence and Quality

179 Significantly more fights were observed in the presence of virgin females than in the presence 180 of mated females or in the absence of females $\left(F_{2,97}=5.79, \mathrm{P}=0.004\right.$, Fig. 1$)$. This was partly 181 explained by the higher incidence of fighting in the presence of a virgin female (74.2\%) than 182 with mated or no female (44.1 and $42.9 \%$, respectively). In addition, the latency to fight was shorter in the presence of virgin females than in the presence of mated females or in the absence of females (Cox's proportional hazards analysis: Risk $=0.448,95 \%$ CI $0.233-0.860, P=0.016$,

Fig. 2), and fights also tended to last longer when there was a virgin female present (Kruskal Wallis $H=5.56, \mathrm{DF}=2, P=0.062$; Fig. 3).

The presence or quality of a female did not influence the incidence of paralysis at the end of the 30 min observation period $\left(G_{2}=1.437, \mathrm{P}=0.487\right)$ when on average $6 \%$ of pairs had one male paralysed, nor did it affect the incidence of paralysis and/or death after 24 hours $\left(G_{2}=2.839, P\right.$ $=0.242$ ), where overall $97 \%$ of pairs had at least one male either paralysed or dead, mostly represented by dead (90.9\% of pairs). Single males routinely suffer 3\% mortality within 24 hours (Zenner et al. 2014).

Moreover, the number of copulations (mating events at vulva) was higher when the female was virgin than mated (mated females: $0.88 \pm 0.18$, virgin females: $1.74 \pm 0.26, F_{1,63}=7.322, \mathrm{P}=$ $0.009)$. 
After $24 \mathrm{~h}$, paralysis or death was recorded in all $(N=21)$ drops where the resident male was mated, but in just $70.8 \%(17 / 24)$ of the drops where the virgin male was resident (Fisher's exact test, $P=0.01)$. For the 38 pairs where there was paralysis or death after $24 \mathrm{~h}$, we investigated whether male mating status and prior residency affected the contest outcome. Mated and resident males were more likely to win (logistic regressions for male mating status: $G_{1,34}=$ 75.13, $P<0.001$; male residency: $G_{1,34}=10.313$, P <0.001) (Figure 4). The effect of male mating status was particularly strong: mated males won $92.1 \%$ of fights overall. The interaction between male mating status and drop residency was not significant $\left(G_{1,34}=0, \mathrm{P}=0.991\right)$.

\section{DISCUSSION}

The presence of a female can lead to escalated male fighting, as it has shown in spiders and parasitoid wasps (Wells 1988; Jackson et al. 2006; Liu et al. 2017). Moreover, the motivation to fight and intensity of fights, and consequently the cost of fighting, is adjusted according to the perceived value of the resource (Parker 1974; Maynard- Smith \& Parker 1976; Arnott \& Elwood 2008; Enquist \& Leimar 1987). In our study we found that not only the presence but also the quality of females had an influence on fighting behaviour of male $S$. longicaudum nematodes; fighting was more intense in the presence of a virgin female, during our 30 min observation period. In other empirical studies, males similarly exhibited significantly more aggressive behaviours, and fights were more intense in the presence of virgin females over mated ones in parasitoid wasps (Liu \& Hao 2019), wolf spiders (Hoefler et al. 2008) and Sierra dome spiders (Keil \& Watson 2010). The fact that a virgin (but not a mated) female enhances competition between male $S$. longicaudum suggests either that females mate only once, or that there is sperm competition with first male precedence (Birkhead \& Moller 1998; Simmons 2001). Sperm precedence has been documented in 
nematodes including Caenorhabditis elegans (LaMunyon \& Ward 1995; Ward \& Carrel 1979). Mated female steinernematids no longer attract males over a distance (Lewis et al. 2002; Hartley 2017), and in our experiment mated females received fewer mating attempts (sperm transfer was not confirmed) than virgins, suggesting at least a reduction in attractiveness. Female steinernematids have at most a short window of availability for mating, with a period of egg-laying succeeded by egg-hatch in utero and subsequent death ("endotokia matricida") (Poinar 1990). The exceptionally large macrosperm of S. longicaudum are suggestive of intense sperm competition (LaMunyon \& Ward 1999). Because the cost of fighting is high, selection favours individuals that can assess the value of the resource and adjust their competitive behaviour accordingly (Parker 1974; Maynard-Smith \& Parker 1976; Arnott \& Elwood 2008). When mates are limited over time and space and their value is equal or higher than the future, then a major part of a male contestant's lifetime reproductive success is at stake and it is predicted that fights can escalate to death (Enquist \& Leimar 1987, 1990). In such cases, fights might ensue irrespective of the quality of the mates, since future opportunities for reproduction are low, but our results show that male S. longicaudum nematodes assess the quality of the females and adjust their fighting behaviour. We suggest that mated females, due to either once-off mating or intense sperm competition, might simply not represent a valuable resource worth fighting to death for.

Differences in the quantity and quality of food or mates lead to an 'objective' assessment of the value of the contested resource, whereas internal state dictates the subjective assessment of the resource value (Enquist \& Leimar 1987; Arnott \& Elwood 2008). In dyadic fights between mated $v s$ virgin males, the mated males were more competitive, resulting in paralysis and death of the virgin male in over $90 \%$ of cases. Mating could enhance fighting skills in nematodes, since similar coiling movements of males around females during copulation are used to lock, paralyse and consequently lead to death of their opponents. 
Increased fighting skills enhance resource holding potential (Briffa \& Lane 2017).

Alternatively, mating in males can result in an increased assessment of fighting ability or an overestimation of the contested resource value (Killian \& Allen 2008; Yasuda et al. 2015). Mating experience has similar effects to 'winning a fight' experience, which is expected in turn to raise the subjective value of a female in future contests (Hsu et al. 2006).

Contests are frequently asymmetrical; one such asymmetry is between territory owners or residents, and intruders. In such cases, it is usually the resident that wins (Hardy \& Briffa 2013). Owner-intruder asymmetry is less likely to affect fighting outcome when the ratio of future to current reproduction is low (Enquist \& Leimar 1990). The relationship between male residency and increased competitive ability that was observed in our experimental conditions might be explained by the fact that the resident males are more adapted to the environment (which is comprised of bacterial/female pheromone odours) of the drop on which they reached adulthood than the intruder males. The extent to which residency effects for male entomopathogenic nematodes occurs in nature is unclear; male entomopathogenic nematodes compete in a restricted space, an insect cadaver, in which it might sometimes be difficult to claim residency. However, larger insect cadavers such as wax moth (G. mellonella) may be large enough to allow some degree of compartmentalization or localization of residents, because at the time the invading nematodes are adult, the wax moth cadaver retains internal structural integrity, allowing physical compartmentalization of individuals within it. Regions of the cadaver could also be chemically differentiated, especially if colonized by nematodes derived from different lines of free-foraging IJs e.g. those that exited from different natal host species or have different bacterial strains and/or chemical signature. Another source of odours that could differentiate space within a cadaver is the female residents. Female $S$. longicaudum are relatively immobile, tending to coil in situ, while males are active and attracted by female pheromones (Hartley 2017). Thus, it is likely that a "territory" or patch is defined by the area 
of the cadaver influenced by a female's odour, at least in a cadaver with a relatively low population density, and such a patch could be defended by a resident male. The increased probability in Experiment 2 of the resident male winning a fight in drops in which the resident was mated might be due to residual pheromones from virgin females increasing the perceived resource value of the drop. Mated S. longicaudum males fight more in the presence of a virgin female, as shown in Experiment 1, and female S. longicaudum secrete pheromones that affect males behaviourally and physiologically even when no female is present (Ebssa et al. 2008; Hartley 2017). Female pheromones enhance aggression in male arthropods including crabs, (Smith et al. 1994; Sneddon et al. 2003), crickets (Buena \& Walker, 2008) and parasitoids (Liu \& Hao 2019). However, female pheromones cannot be the explanation for the increased probability of the resident winning in the drops where the resident was virgin, since these drops had not previously held a female. Both mated and virgin males were more likely to win when resident, but since mated residents may have experienced pheromone, but virgin residents did not, the lack of an interaction between the effects of male mating status and residency may in fact point to an asymmetrical effect of female pheromone on the aggression of mated and virgin males. There are also some observations wherein female presence has a differential effect on fighting intensity of unmated and mated S. longicaudum males (Kapranas \& Griffin n.d.). Such differential effects of female presence or pheromones may be related to the fact that $S$. longicaudum that have had no female presence are not immediately ready to mate (Ebssa et al. 2008).

Fatal fighting is expected to ensue whenever the value of the resource outbalances the risk of injury, as is the case of entomopathogenic nematode males who have to fight for access to females which are limited in space and time. Our study shows that competitor males adjust their fighting behaviour according to the objective (presence and quality of females) and subjective (male mating experience) components of resource value. Male mating 
experience could enhance the fighting ability (resource holding potential) but also its influence on fighting ability is confounded by resource value components.

\section{REFERENCES}

Abe, J., Kamimura, Y. \& Shimada, M. 2005. Individual sex ratios and offspring emergence patterns in a parasitoid wasp, Melittobia australica (Eulophidae), with superparasitism and lethal combat among sons. Behavioral Ecology and Sociobiology, 57, 366-373.

\section{Alsaiyah, M.A.M, Ebssa, L., Zenner A, O'Callaghan, K.M. \& Griffin, C.T. 2009. Sex} ratios and sex-biased infection behaviour in the entomopathogenic nematode genus Steinernema. International Journal for Parasitology, 39, 725-734.

Ancona, S., Drummond, H. \& Zaldivar-Rae, J. 2010. Male whiptail lizards adjust energetically costly mate guarding to male-male competition and female reproductive value. Animal Behaviour, 79, 75-82.

Andersson, M. 1994. Sexual selection. Princeton (NJ): Princeton University Press.

Anderson, C., Cremer, S. \& Heinze, J. 2003. Live and let die: why fighter males of the ant Cardiocondyla kill each other but tolerate their winged rivals. Behavioural Ecology, 14, 54-62.

Arnott, G. \& Elwood, R.W. 2008. Information gathering and decision making about resource value in animal contests. Animal Behaviour, 76, 529-542.

Arnott, G. \& Elwood, R.W. 2009. Assessment of fighting ability in animal contests. Animal Behaviour, 77, 991-1004.

Birkhead, T.R. \& Møller, A.P. 1998. Sperm Competition and Sexual Selection. Academic Press, London. Pp. 826. 
Briffa, M., Hardy, I.C.W., Gammell, M.P., Jennings, D.J., Clarke, D.D. \& Goubault, M. 2013 Analysis of animal contest data. In: Hardy ICW, Briffa M, editors. Animal contests Cambridge (UK): Cambridge University Press. p. 47-85.

Briffa, M. \& Lane, S.M. 2017. The role of skill in animal contests: a neglected component of fighting ability. Proceedings of the Royal Society B, 284, 20171596.

Briffa, M. \& Sneddon, L.U. 2007. Physiological constraints on contest behaviour. Functional Ecology, 21, 627-637.

Brown, W.D., Smith, A.T., Moskalik, B.\& Gabriel, J. 2006. Aggressive contests in house crickets: size, motivation and the information content of aggressive songs. Animal Behaviour, 72, 225-233.

Brown, W.D., Chimenti, A.J. \& Siebert, J.R. 2007. The payoff of fighting in house crickets: motivational asymmetry increases male aggression and mating success. Ethology, 113, 457-465.

Buena, L.J. \& Walker, S.E. 2008. Information asymmetry and aggressive behaviour in male house crickets, Acheta domesticus. Animal Behaviour, 75, 199-204.

Crespi, B.J. 1988. Risks and benefits of lethal male fighting in the colonial, polygynous thrips Hoplothrips karnyi (Insecta: Thysanoptera). Behavioral Ecology Sociobiology, 22, 293-301.

Cook, J.M. \& Bean, D. 2006. Cryptic male dimorphism and fighting in a fig wasp. Animal Behaviour, 71, 1095-1101.

Dick, J.T.A \& Elwood, R.W. 1990. Symmetrical assessment of female quality by male Gammarus pulex (amphipoda) during struggles over precopula females. Animal Behaviour, 40, 877-883.

Dillman, A.R. \& Sternberg, P.W. 2012. Quick guide: entomopathogenic nematodes. Current Biology, 22, 430-431. 
DeCarvalho, T.N., Watson P.J. \& Field SA. 2004. Costs increase as ritualized fighting progresses within and between phases in the sierra dome spider, Neriene litigiosa. Animal Behaviour, 68, 473-482.

Dugatkin, L.A. \& Dugatkin, A.D. 2011. Overestimating resource value and its effects on fighting decisions. PLoS ONE 6:e19924

Ebssa, L., Dix, I. \& Griffin, C.T. 2008. Female presence is required for male sexual maturity in the nematode Steinernema longicaudum. Current Biology, 18, R997-R998.

Enquist, M. \& Leimar, O. 1987. Evolution of fighting behavior-the effect of variation in resource value. Journal of Theoretical Biology, 127, 187-205.

Enquist, M. \& Leimar, O. 1990. The evolution of fatal fighting. Animal Behaviour, 39,1-9.

Hardy, I.C.W \& Brifa M. 2013. Animal contests. Cambridge (UK): Cambridge University Press.

Hamilton, W.D. 1979. Wingless and fighting males in fig wasps and other insects. In: Blum MS, Blum NA, editors. Sexual selection and reproductive competition in insects. London: Academic Press. p. 167-220.

Hartley, C.J. 2017. Pheromones in entomopathogenic nematodes: effects on dispersal and reproductive behaviours. $\mathrm{PhD}$ Thesis, Maynooth University.

Hoefler, C.D., Guhanarayan, G., Persons, M.H., Rypstra, A.L. 2009. The interaction of female condition and mating status on male-male aggression in a wolf spider. Ethology, 115, $331-338$.

Hsu, Y., Earley, R.L. \& Wolf, L.L. 2006. Modulation of aggressive behaviour by fighting experience: mechanisms and contest outcomes. Biological Reviews, 81, 33-74.

Innocent, T.M., West, S.A, Sanderson, J.L., Hyrkkanen, N. \& Reece, S.E. 2011. Lethal combat over limited resources: testing the importance of competitors and kin. Behavioural Ecology, 22, 923-931 
Innocent, T.M., Savage, J., West, S.A. \& Reece SE. 2007. Lethal combat and sex ratio evolution in a parasitoid wasp. Behavioural Ecology, 18, 709-715.

Jackson, R.R., Walker, M.W., Pollard, S.D. \& Cross, F.R. 2006. Influence of seeing a female on the male-male interactions of a jumping spider, Hypoblemum albovittatum. Journal of Ethology, 24, 231-238.

Judge, K.A, Ting, J.J., Schneider, J. \& Fitzpatrick, M.J. 2010. A lover, not a fighter: mating causes male crickets to lose fights. Behavioral Ecology and Sociobiology, 64, 1971-1979.

Kapranas, A \& Griffin, C.T. n.d. male-male fatal fights in groups of entomopathogenic nematodes: female presence modulates differentially fighting behaviour in mated and virgin males. Unpublished manuscript.

Kapranas, A., Maher, A.M.D. \& Griffin, C.T. 2016. Higher relatedness mitigates mortality in a nematode with lethal male fighting. Journal of Evolutionary Biology, 29, 344-351.

Kasumovic, M.M., Mason, A.C., Andrade, M.C.B. \& Elias, D.O. 2011. The relative importance of RHP and resource quality in contests with ownership asymmetries. Behavioral Ecology, 22, $39-45$

Kaya, H.K. \& Gaugler, R. 1993. Entomopathogenic nematodes. Annual Review of Entomology, 38, 181-206.

Kaya, H.K., \& Stock, S.P. 1997. Techniques in insect nematology. In Lacey, editor. Manual of Techniques in Insect Pathology. New York (USA), Academic Press, p. 281-324.

Kemp, D.J. 2006. Ageing, reproductive value, and the evolution of lifetime fighting behaviour. Biological Journal of the Linnean Society, 88, 565-578.

Keil, P.L \& Watson, P.J. 2010. Assessment of self, opponent and resource during male-male contests in the sierra dome spider, Neriene litigiosa: Linyphiidae. Animal Behaviour, 80, 809-820. 
Killian, K.A. \& Allen, J.R. 2008. Mating resets male cricket aggression. Journal of Insect Behaviour, 21, 535-548.

Kokko, H. 2013. Dyadic contests: modelling fights between two individuals. In: Hardy ICW, Briffa M, editors. Animal contests Cambridge (UK): Cambridge University Press. p. 532.

LaMunyon, C.W. \& Ward, S. 1995. Sperm precedence in a hermaphroditic nematode (Caenorhabditis elegans) is due to competitive superiority of male sperm. Experientia, $51,817-823$.

LaMunyon, C.W. \& Ward, S. 1999. Evolution of sperm size in nematodes: sperm competition favours larger sperm. Proceedings of the Royal Society B, 266, 263-267.

Lewis, E.E, Barbarosa, B. \& Gaugler, R. 2002. Mating and sexual communication by Steinernema carpocapsae (Nemata: Steinernematidae). Journal of Nematology, 34, $328-331$.

Liu, P.C., Wei, J.R., Tian, S. \& Hao, D.J. 2017. Male-male lethal combat in the quasigregarious parasitoid Anastatus disparis (Hymenoptera: Eupelmidae). Scientific Reports, 7, 11875.

Liu, P. \& Hao, D.J. 2019. Effect of variation in objective resource value on extreme male combat in a quasi-gregarious species, Anastatus disparis. BMC Ecology, 19, 21

Mariette, M.M., Cathaud, C., Chambon, R. \& Vignal, C. 2013. Juvenile social experience affects pairing success at adulthood: congruence with the loser effect? Proceedings of the Royal Society B, 280, 20131514.

Matthews, R.W., Gonzalez, J.M., Matthews, J.R. \& Deyrup LD. 2009. Biology of the parasitoid Melittobia (Hymenoptera: Eulophidae). Annual Review of Entomology, 54, 251-266.

Maynard Smith, J. \& Price, G.R. 1973. The logic of animal conflict. Nature, 246, 15-18. 
Maynard Smith, J. \& Parker, G.A. 1976. The logic of animal contests. Animal Behaviour, 24, 159-175.

Moya-Larano, J. \& Wise, D.H. 2000. Survival regression analysis: a powerful tool for evaluating fighting and assessment. Animal Behaviour, 60, 307-313.

Parker, GA. 1974. Assessment strategy and the evolution of fighting behaviour. Journal of Theoretical Biology, 47, 223-243.

Pérez-Staples, D., Martínez-Hernández, M.G. \& Aluja, M. 2010. Male age and experience increases mating success but not female fitness in the Mexican fruit fly. Ethology, 116, $778-786$.

Piper, W.H., Walcott, C., Mager, J.N. \& Spilker, F.J. 2008. Fatal battles in common loons: a preliminary analysis. Animal Behaviour, 75, $1109-1115$.

Poinar, G.O. 1990. Biology and taxonomy of Steinernematidae and Heterorhabditidae. in Gaugler R, Kaya HK editors. Entomopathogenic nematodes in biological control Boca Raton, FL, CRC Press: Pp. 23-62.

Rico-Guevara, A. \& Hurme, L. 2019. Intrasexually selected weapons. Biological Reviews, 94, 60-101.

Sato, Y., Egas, M. \& Sabelis, M.W. \& Mochizuki, A. 2013. Male-male aggression peaks at intermediate relatedness in a social spider mite. Ecology and Evolution, 3, 2661-2669.

Simmons, LW. 2001. Sperm Competition and Its Evolutionary Consequences in the Insects. Princeton Univ. Press, Princeton, NJ.

Smith, I.P., Huntingford, F.A., Atkinson, R.J.A. \& Taylor, A.C. 1994. Mate competition in the velvet swimming crab Necora puber: effects of perceived resource value on male agonistic behavior. Marine Biology, 120, 579-584. 
Sneddon, L.U., Huntingford, F.A., Taylor, A.C., \&Clare, A.S. 2003. Female sex pheromone-mediated effects on behavior and consequences of male competition in the shore crab (Carcinus maenas). Journal of Chemical Ecology, 29, 55-70.

Stockermans, B.C. \& Hardy, I.C.W. 2013. Subjective and objective components of resource value additively increase aggression in parasitoid contests. Biology Letters, 9, 20130391

Ward, S. \& Carrel, J.S. 1979. Fertilization and sperm competition in the nematode Caenorhabditis elegans. Developmental Biology, 73, 304-321

Wells, M.S. 1988. Effects of body size and resource value on fighting behaviour in a jumping spider. Animal Behaviour, 36, 321-326.

Yasuda, C.I., Matsuo, K., Wada, S. 2015. Previous mating experience increases fighting success during male-male contests in the hermit crab Pagurus nigrofascia. Behavioral Ecology and Sociobiology, 69, 1287-1292.

Zenner, A.N.R.L, O'Callaghan, K.M., Griffin, C.T. 2014. Lethal fighting in nematodes is dependent on developmental pathway: male-male fighting in the entomopathogenic nematode Steinernema longicaudum. PLoS One, 9, e89385.

Zhang, S., Ai, H. \& Li, D. 2019. Mating changes a male contestant from a loser to a winner in male-male competition in a wolf spider. Biological Journal of the Linnean. Society, $128,83-92$ 
473 Figure 1 Fights between two mated males, in the presence or absence of a female within 30

474

475 minutes. Bars show average values with asymmetrical, poisson-distributed errors. Bars with accompanied by the same letter are not significantly different (post-hoc multiple comparison tests with Bonferroni adjustment, $\alpha=0.05)$.

Figure 2. Latency to first fight between two mated males in the presence or absence of a female within 30 minutes.

Figure 3. Time spent fighting by two males in the presence or absence of a female within 30 minutes. Data are represented as box and whisker plots with median (horizontal line), 25-75 percentiles (boxes), ranges for the bottom $25 \%$ and the top $25 \%$ of the data values (whiskers).

Figure 4. Probability of winning of mated and virgin males in pairs of one mated and one virgin adult male set up either in the drop in which mated male had been reared and mated or in the drop in which the unmated male had been reared. Bars show estimated average values with asymmetrical, binomially distributed standard errors

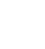
8

(1) 
496

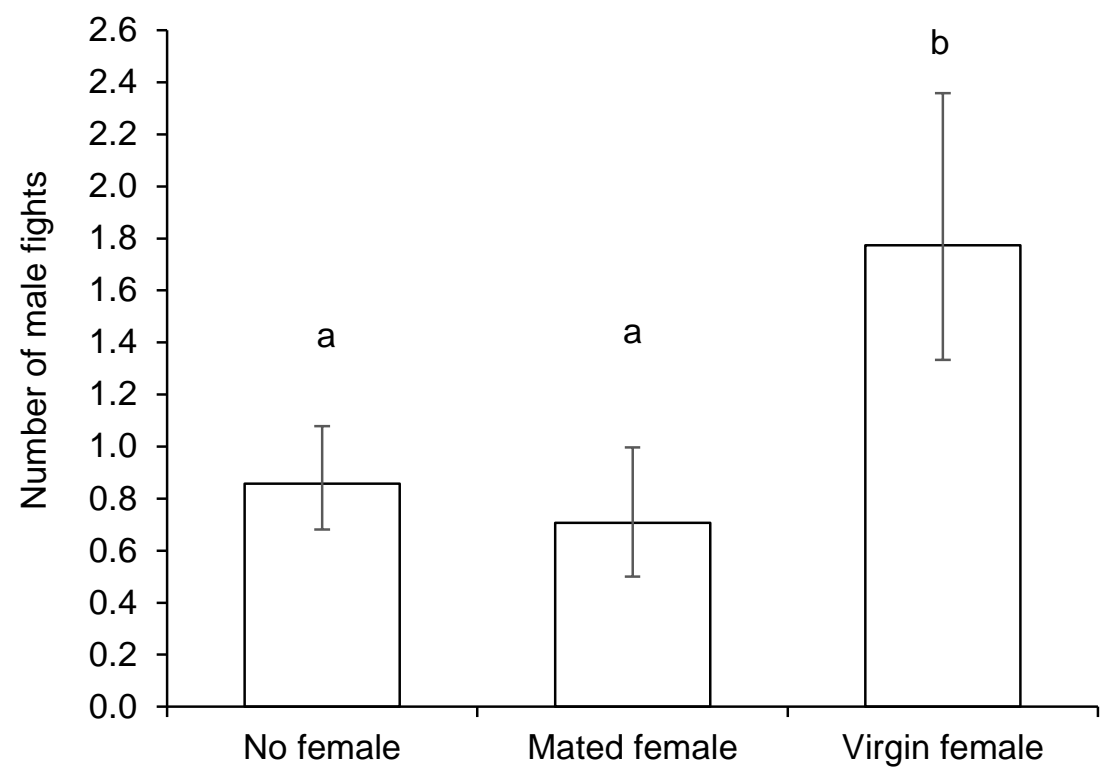

497

498

499

500

501

502 


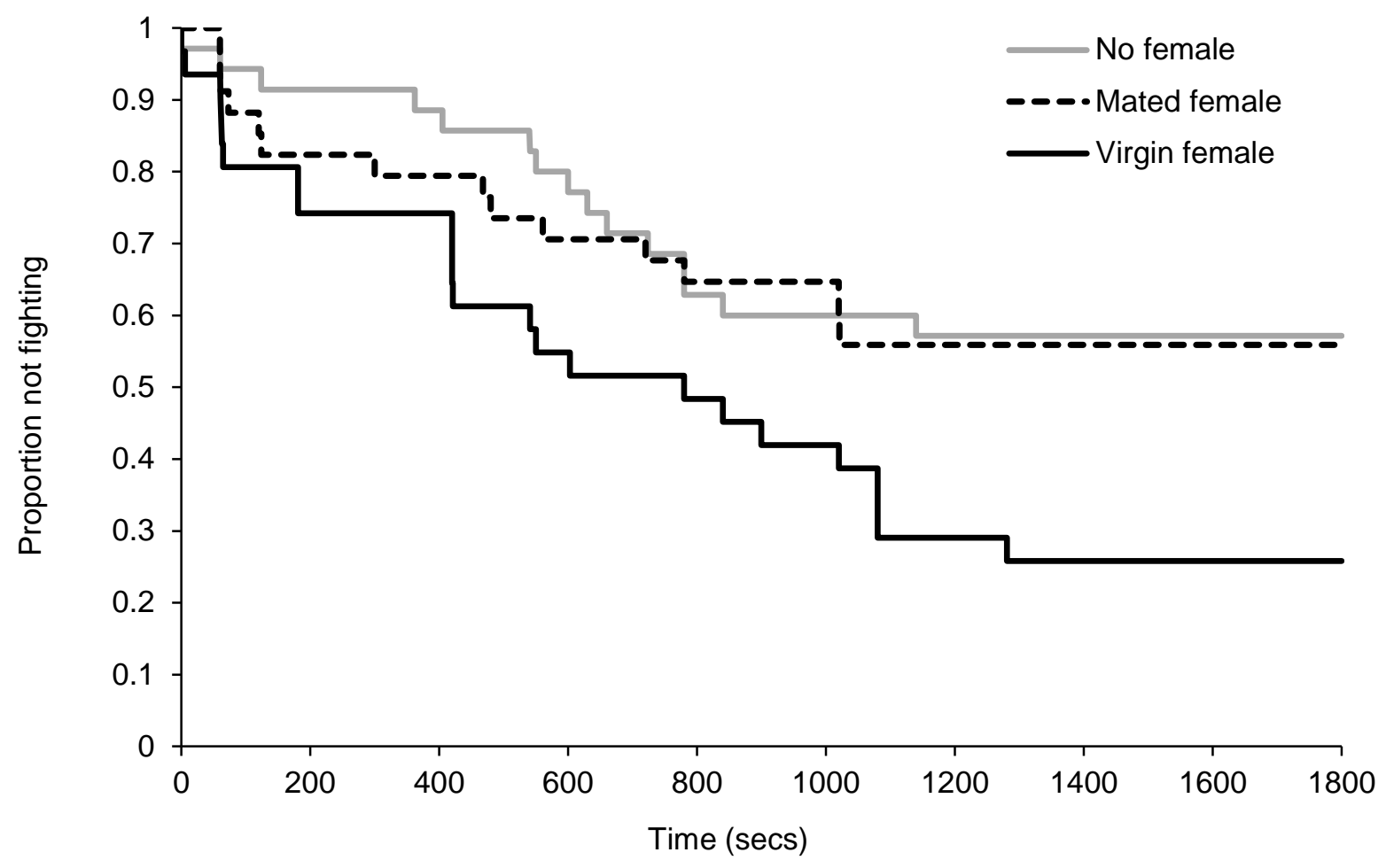

504

505

506

507

508

509 


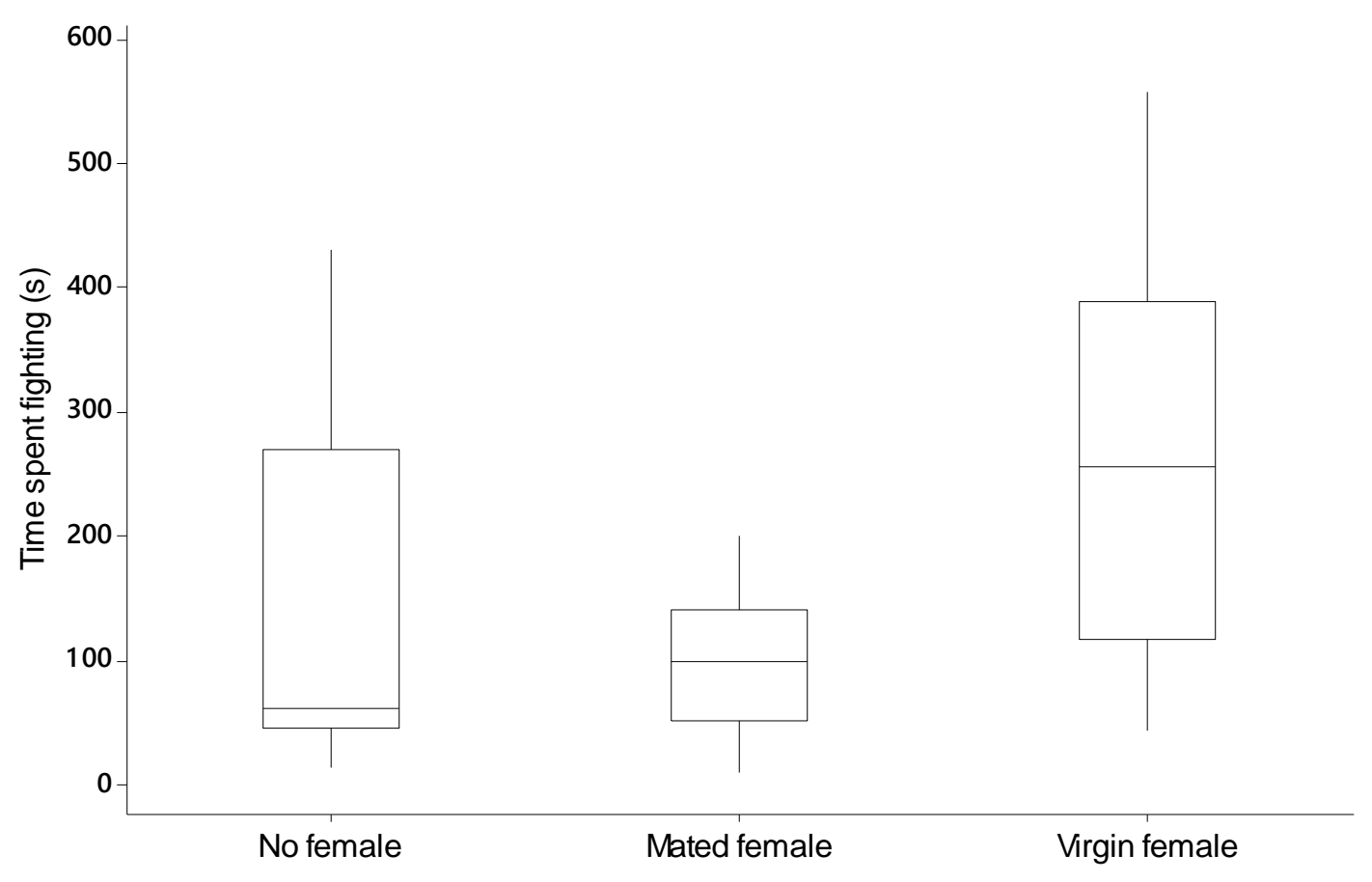

510

511

512

513

514

515

516

517

518

519

520

521

522

523

524

525 


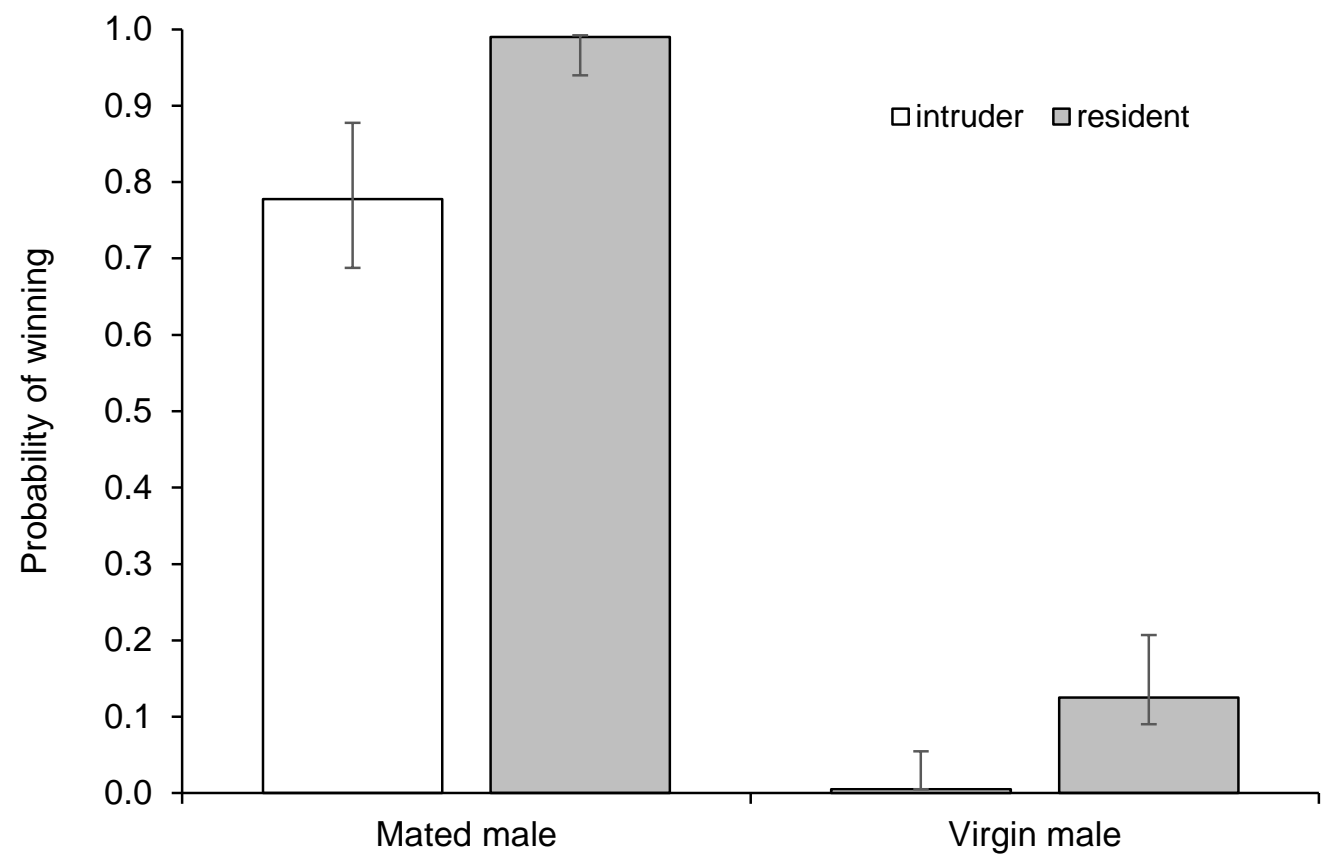




\section{Objective and subjective components of resource value in lethal fights between male entomopathogenic nematodes}

\section{ABSTRACT}

Males sometimes engage in fights over contested resources such as access to mates; in this case, fighting behaviour may be adjusted based on the value they place on the females.

Resource value RV can have two components. Males can assess the quality of females, which constitutes an objective assessment of RV. Internal state such as previous mating experience can also influence motivation to fight thus constituting a subjective assessment of RV. If mating opportunities are scarce and available females have a major impact on the lifetime reproductive success of males, then fighting can be fatal; in this situation it is uncertain whether males would adjust fighting behaviour based on RV. We found that both female quality i.e., virginity (objective component of RV) and male mating status (subjective component of RV) influence fighting intensity between males of the entomopathogenic nematode Steinernema longicaudum which engage in lethal fights. Male nematodes were more likely to engage in fighting and fought longer and more frequently in the presence of virgin (high quality) females than in the presence of mated (lower quality) females. Male mating status was also found to influence fighting behaviour; mated males were the winners in staged fights between mated and virgin males. Mated males may have superior fighting ability (enhanced resource holding potential RHP), but RV asymmetries between mated and virgin males cannot be excluded. Males were more likely to win when they were resident, but we did not find a significant interaction effect between male mating and residency status. Key words: entomopathogenic nematodes, female quality, lethal fights, male mating status, resource value. 


\section{INTRODUCTION}

Animals frequently engage in contests over resources that impact their fitness, such as mates, territories or nesting sites (Andersson 1994). Amongst the most important factors influencing the extent and outcome of contest behaviour are the resource holding potential of the contestants, the value of the resource and the costs of fighting (Parker 1974; Arnott \& Elwood 2008; Hardy \& Briffa 2013). Resource holding potential RHP (fighting ability) of the contestants may depend on their weaponry, energy reserves and body size (Parker 1974; Arnott \& Elwood 2009; Hardy \& Briffa 2013; Rico-Guevara \& Hurme 2019). Resource value RV has two components: objective and subjective; Intrinsic properties of the resource that will yield a certain fitness gain to a successful competitor constitute the objective components of resource value, while the value of a given resource may vary for each contestant depending on its own internal state and prior experience (subjective component of resource value) (Enquist \& Leimar 1987; Arnott \& Elwood 2008). These components of resource value may simultaneously influence the ultimate value of the resource (Stockermans \& Hardy 2013).

Objective and subjective components of resource value have been widely studied in contests between males for mates, where the contested resource is receptive females. When females are scarce, males may be more motivated to fight, but this motivation can also depend on female quality which can be based on size (larger females are more fecund), nearness to moult or mating status (Crespi 1988; Dick \& Elwood 1990; Arnott \& Elwood 2008; Keil \& Watson 2010; Hoefler et al. 2009; Ancona et al. 2010; Kasumovic et al. 2011). Furthermore, males' internal state, such as their own mating status, can influence subjectively the value that they place on the contested resource (i.e., mates) (Arnott \& Elwood 2008). Mated males may become less aggressive and more likely to lose at contests due to the energetic cost of mating (Brown et al. 2006, 2007; Judge et al. 2010). On the other hand, previous mating experience has been shown to increase a male's aggression and fighting success in several animal taxa 
because of changes in the male's self-assessment of RHP and perception of the resource value, that are similar to winner/loser effects (Killian and Allen 2008; Yasuda et al. 2015, Dugatkin \& Dugatkin 2011; Zhang et al., 2019). If an animal wins a contest then its perception of fighting ability increases and it is more likely to initiate future fights and win them, whereas losers lower their RHP perception, are less aggressive and more likely to lose (Hsu et al. 2006). Mating status is also related to the residual reproductive value (number of future offspring) which is predicted to influence male investment in fighting (Kemp 2006). An unmated male can be more aggressive and more motivated to fight because future mating opportunities are of greater value to him, whereas a mated male may be less willing to engage in costly fighting (Kemp 2006).

Fighting is costly, risking injury and using time and energy that could be used in mating or other activities (Maynard Smith \& Price 1973; Briffa \& Sneddon 2007). As the value of the contested resource increases, the cost of fighting can also increase (Enquist \& Leimar 1987; Kokko 2013). If the contested resource has a major impact on the lifetime reproductive success of the the contenstants, such as limited females, then fights can escalate to serious injury and even death (Enquist \& Leimar 1987, 1990; Maynard Smith \& Parker 1976). Lethal male fighting has been recorded in some vertebrates (e.g., Piper et al. 2008) and numerous arthropods, particularly arachnids (DeCarvalho et al. 2004; Sato et al. 2013) and hymenopterans (Anderson et al. 2003; Matthews et al. 2009; Cook \& Bean 2006; Hamilton 1979; Innocent et al. 2007; Innocent et al. 2011) and lately in entomopathogenic nematodes (Zenner et al. 2014; Kapranas et al. 2016). Whereas contested resource availability, such as potential mates, is critical in prompting lethal fights (Enquist \& Leimar 1990), it is unclear to what extent the contestants also assess the quality of resource in such species. When mating opportunities for males are extremely limited then their motivation to fight would be expected to be independent of resource quality even if the odds of dying in a fight are high (Enquist \& 
Leimar 1990). Amongst parasitoid hymenopterans with lethal male combat, some species adjust fighting behaviour according to the value of the resource (Liu \& Hao 2019), while others do not (Innocent et al. 2011).

Here we investigate the effect of objective and subjective resource value on lethal contests of male entomopathogenic nematodes Steinernema longicaudum Shen and Wang.

We are able to manipulate the mating status of the contestant males and also the quality of the contested resource by staging dyadic contests in a controlled environment (drops of haemolymph of their insect host). First, we assess how the presence/absence and quality of available females (objective components of resource value) influence fighting behaviour between mated males. We predict that the presence of a female, especially a virgin, will increase the frequency and/or severity of fighting in S. longicaudum. Then, we assess whether male mating status (subjective components of resource value) influences the contest outcome. We do not have a directional prediction of how mating influences fighting, but we hypothesize that either mated or virgin males will have a consistent advantage over the other, and this will provide insights regarding how male nematodes assess the value of their mates and whether mating status influences fighting ability.

\section{MATERIALS AND METHODS}

\section{Nematode Reproductive Biology and Lethal Fighting.}

Infection by entomopathogenic nematodes including $S$. longicaudum begins when freeforaging infective juveniles (IJs) enter an insect host and release their symbiotic bacteria that turn the host insect into a cadaver. In S. longicaudum, IJs develop into amphimictic males and females, with a sex ratio that is slightly female biased (Alsaiyah et al. 2009). Two or more generations develop until the cadaver is crowded, prompting the production of IJs that exit in 
search of other hosts (Kaya \& Gaugler 1993; Dillman \& Sternberg 2012). In S. longicaudum it was shown that males are aggressive towards each other and engage in lethal fights (Zenner et al. 2014). During male-male encounters, an aggressor coils its tail end around a victim, with the copulatory spicules towards the victim's body. If not gripped close to the tail, the victim may counter-attack, wrapping its tail around the aggressor. Grappling encounters frequently end when the grasped male ceases to move part or all of its body, which may happen within minutes (Zenner et al. 2014). Such worms usually die, though partially paralyzed worms occasionally recover movement. The cuticle is sometimes punctured, but paralysis and death occur also without puncture, apparently due to damage to internal organs.

\section{Nematode Cultures and Behavioural Assays}

Steinernema longicaudum (strain CB2B) cultures were routinely maintained using standard procedures by passage through late instar Galleria mellonella (wax moth) larvae (Kaya \& Stock 1997) at $27^{\circ} \mathrm{C}$. Infective juveniles were stored in tap water at $20^{\circ} \mathrm{C}$. We obtained adult males for our experiments by placing IJs individually in $25 \mu 1$ hanging drops of haemolymph from G. mellonella larvae which provides a suitable environment for development to adulthood (Kaya \& Stock 1997; Zenner et al. 2014). The hanging drops were placed on the lid of a Petri dish which was then inverted over a water-filled Petri dish $(6 \mathrm{~cm} \mathrm{diam}$.) to prevent desiccation. The IJs in the hanging drops develop to adulthood within 3 days at $27^{\circ} \mathrm{C}$. Adult males can be distinguished by their copulatory spicules and their smaller size whereas females are larger in size and bear vulva. We used three days old males and females in our experiments.

\section{Experiment 1: Effects of Female Mating Status}


All males used in this experiment were mated. We placed each individual naïve male for 1620 hours with 2 naïve females to mate. We then removed the females, and successful mating was subsequently confirmed by the production of progeny. We removed two adult males from their hanging drops and placed them immediately, in pairs, back in the drop from which one member of the pair had been taken. Thus, one worm was "resident" and one an "intruder", but the identity of each was not tracked, as there were no clear visual differences between them. Worms were assigned to the following treatments: (i) 2 mated males with a mated female $(N$ =34); (ii) 2 mated males with a virgin female (same age as mated female) $(N=31)$; (iii) 2 mated males without a female $(N=35)$. A mating attempt was recorded when a male coiled around the female at the vulva; insertion of spicules into the vulva was difficult to observe due to the coiling of the male around the female. A fight was recorded once one male coiled tightly around another and then let go. Continuous observations were made for 30 mins during which the latency to first fight, the incidence (whether at least one fighting event occurred), number and (for a subsample) duration of fights were recorded. Paralysis and/or death of the males was recorded at the end of the observation and after 24 hours.

\section{Experiment 2: Effects of Male Mating Status}

In S. longicaudum, males that have been with a female can be distinguished from those that have not, based on the presence of sperm in the seminal vesicle, visible through the body wall (Ebssa et al., 2008); thus, mating status of individual males in a pair could be recognized. In this experiment, we placed together an adult male that had mated and a virgin one. Mated males were obtained by placing two females in the drop of an individually reared adult male for 24 hours, after which the females were removed to a different drop and observed for later progeny production. We set up pairs of one mated and one virgin adult male either in the drop in which the mated male had been reared and mated $(N=21)$ or in the drop in which the 
unmated male had been reared $(N=24)$. In this case, since mated and unmated males differed in appearance, the identity of "resident" and "intruder" could also be traced. After 24 hours we observed which worms showed signs of paralysis or death. Individual males were identified as the mated or virgin member of the pair by examining for the presence of sperm using a Nikon Optiphot microscope (x40).

\section{Statistics}

Analysis of factors influencing the number of fights, as well copulations observed in our assays and the probability of paralysis/death were explored with generalized linear models as described in Briffa et al. (2013). To test the hypothesis that objective resource value affects fighting behavior, we used a log-linear analysis which is appropriate for small count data, to assess how female presence and mating status (predictor variables) affected the number of fights (dependent variable). Post-hoc tests among different treatments whenever applicable were adjusted with the Bonferroni correction. The probability of paralysis and/or death at the end of the 30 min observation period and $24 \mathrm{~h}$ post observations was explored with logistic analysis. Duration of fighting in different treatments (no females, mated and virgin females) was analysed with a non-parametric Kruskal Wallis test and latency to fighting was analysed using survival regression analysis (Moya-Larano \& Wise 2000). In the second experiment, we compared the incidence of paralysis/death in contests staged in drops where the resident male was mated versus drops where the resident was a virgin male, by using a Fisher's exact test. For those pairs in which paralysis or death occurred, we used a logistic analysis by randomly picking a focal male (either mated or virgin) in each replicate and tested the effect of residency and mating status (as factors) and their interaction on the probability of the focal male winning the contest (Briffa et al. 2013). All analysis was performed in SPSS v.21 (IBM, Armonk, NY, USA). 
RESULTS

177

Female Presence and Quality

179 Significantly more fights were observed in the presence of virgin females than in the presence 180 of mated females or in the absence of females $\left(F_{2,97}=5.79, \mathrm{P}=0.004\right.$, Fig. 1$)$. This was partly 181 explained by the higher incidence of fighting in the presence of a virgin female (74.2\%) than 182 with mated or no female (44.1 and $42.9 \%$, respectively). In addition, the latency to fight was shorter in the presence of virgin females than in the presence of mated females or in the absence of females (Cox's proportional hazards analysis: Risk $=0.448,95 \%$ CI $0.233-0.860, P=0.016$,

Fig. 2), and fights also tended to last longer when there was a virgin female present (Kruskal Wallis $H=5.56, \mathrm{DF}=2, P=0.062$; Fig. 3).

The presence or quality of a female did not influence the incidence of paralysis at the end of the 30 min observation period $\left(G_{2}=1.437, \mathrm{P}=0.487\right)$ when on average $6 \%$ of pairs had one male paralysed, nor did it affect the incidence of paralysis and/or death after 24 hours $\left(G_{2}=2.839, P\right.$ $=0.242$ ), where overall $97 \%$ of pairs had at least one male either paralysed or dead, mostly represented by dead (90.9\% of pairs). Single males routinely suffer 3\% mortality within 24 hours (Zenner et al. 2014).

Moreover, the number of copulations (mating events at vulva) was higher when the female was virgin than mated (mated females: $0.88 \pm 0.18$, virgin females: $1.74 \pm 0.26, F_{1,63}=7.322, \mathrm{P}=$ 0.009). 
After $24 \mathrm{~h}$, paralysis or death was recorded in all $(N=21)$ drops where the resident male was mated, but in just $70.8 \%(17 / 24)$ of the drops where the virgin male was resident (Fisher's exact test, $P=0.01)$. For the 38 pairs where there was paralysis or death after $24 \mathrm{~h}$, we investigated whether male mating status and prior residency affected the contest outcome. Mated and resident males were more likely to win (logistic regressions for male mating status: $G_{1,34}=$ 75.13, $P<0.001$; male residency: $G_{1,34}=10.313$, P <0.001) (Figure 4). The effect of male mating status was particularly strong: mated males won $92.1 \%$ of fights overall. The interaction between male mating status and drop residency was not significant $\left(G_{1,34}=0, \mathrm{P}=0.991\right)$.

\section{DISCUSSION}

The presence of a female can lead to escalated male fighting, as it has shown in spiders and parasitoid wasps (Wells 1988; Jackson et al. 2006; Liu et al. 2017). Moreover, the motivation to fight and intensity of fights, and consequently the cost of fighting, is adjusted according to the perceived value of the resource (Parker 1974; Maynard- Smith \& Parker 1976; Arnott \& Elwood 2008; Enquist \& Leimar 1987). In our study we found that not only the presence but also the quality of females had an influence on fighting behaviour of male $S$. longicaudum nematodes; fighting was more intense in the presence of a virgin female, during our 30 min observation period. In other empirical studies, males similarly exhibited significantly more aggressive behaviours, and fights were more intense in the presence of virgin females over mated ones in parasitoid wasps (Liu \& Hao 2019), wolf spiders (Hoefler et al. 2008) and Sierra dome spiders (Keil \& Watson 2010). The fact that a virgin (but not a mated) female enhances competition between male $S$. longicaudum suggests either that females mate only once, or that there is sperm competition with first male precedence (Birkhead \& Moller 1998; Simmons 2001). Sperm precedence has been documented in 
nematodes including Caenorhabditis elegans (LaMunyon \& Ward 1995; Ward \& Carrel 1979). Mated female steinernematids no longer attract males over a distance (Lewis et al. 2002; Hartley 2017), and in our experiment mated females received fewer mating attempts (sperm transfer was not confirmed) than virgins, suggesting at least a reduction in attractiveness. Female steinernematids have at most a short window of availability for mating, with a period of egg-laying succeeded by egg-hatch in utero and subsequent death ("endotokia matricida") (Poinar 1990). The exceptionally large macrosperm of S. longicaudum are suggestive of intense sperm competition (LaMunyon \& Ward 1999). Because the cost of fighting is high, selection favours individuals that can assess the value of the resource and adjust their competitive behaviour accordingly (Parker 1974; Maynard-Smith \& Parker 1976; Arnott \& Elwood 2008). When mates are limited over time and space and their value is equal or higher than the future, then a major part of a male contestant's lifetime reproductive success is at stake and it is predicted that fights can escalate to death (Enquist \& Leimar 1987, 1990). In such cases, fights might ensue irrespective of the quality of the mates, since future opportunities for reproduction are low, but our results show that male S. longicaudum nematodes assess the quality of the females and adjust their fighting behaviour. We suggest that mated females, due to either once-off mating or intense sperm competition, might simply not represent a valuable resource worth fighting to death for.

Differences in the quantity and quality of food or mates lead to an 'objective' assessment of the value of the contested resource, whereas internal state dictates the subjective assessment of the resource value (Enquist \& Leimar 1987; Arnott \& Elwood 2008). In dyadic fights between mated $v s$ virgin males, the mated males were more competitive, resulting in paralysis and death of the virgin male in over $90 \%$ of cases. Mating could enhance fighting skills in nematodes, since similar coiling movements of males around females during copulation are used to lock, paralyse and consequently lead to death of their opponents. 
Increased fighting skills enhance resource holding potential (Briffa \& Lane 2017).

Alternatively, mating in males can result in an increased assessment of fighting ability or an overestimation of the contested resource value (Killian \& Allen 2008; Yasuda et al. 2015). Mating experience has similar effects to 'winning a fight' experience, which is expected in turn to raise the subjective value of a female in future contests (Hsu et al. 2006).

Contests are frequently asymmetrical; one such asymmetry is between territory owners or residents, and intruders. In such cases, it is usually the resident that wins (Hardy \& Briffa 2013). Owner-intruder asymmetry is less likely to affect fighting outcome when the ratio of future to current reproduction is low (Enquist \& Leimar 1990). The relationship between male residency and increased competitive ability that was observed in our experimental conditions might be explained by the fact that the resident males are more adapted to the environment (which is comprised of bacterial/female pheromone odours) of the drop on which they reached adulthood than the intruder males. The extent to which residency effects for male entomopathogenic nematodes occurs in nature is unclear; male entomopathogenic nematodes compete in a restricted space, an insect cadaver, in which it might sometimes be difficult to claim residency. However, larger insect cadavers such as wax moth (G. mellonella) may be large enough to allow some degree of compartmentalization or localization of residents, because at the time the invading nematodes are adult, the wax moth cadaver retains internal structural integrity, allowing physical compartmentalization of individuals within it. Regions of the cadaver could also be chemically differentiated, especially if colonized by nematodes derived from different lines of free-foraging IJs e.g. those that exited from different natal host species or have different bacterial strains and/or chemical signature. Another source of odours that could differentiate space within a cadaver is the female residents. Female $S$. longicaudum are relatively immobile, tending to coil in situ, while males are active and attracted by female pheromones (Hartley 2017). Thus, it is likely that a "territory" or patch is defined by the area 
of the cadaver influenced by a female's odour, at least in a cadaver with a relatively low population density, and such a patch could be defended by a resident male. The increased probability in Experiment 2 of the resident male winning a fight in drops in which the resident was mated might be due to residual pheromones from virgin females increasing the perceived resource value of the drop. Mated S. longicaudum males fight more in the presence of a virgin female, as shown in Experiment 1, and female S. longicaudum secrete pheromones that affect males behaviourally and physiologically even when no female is present (Ebssa et al. 2008; Hartley 2017). Female pheromones enhance aggression in male arthropods including crabs, (Smith et al. 1994; Sneddon et al. 2003), crickets (Buena \& Walker, 2008) and parasitoids (Liu \& Hao 2019). However, female pheromones cannot be the explanation for the increased probability of the resident winning in the drops where the resident was virgin, since these drops had not previously held a female. Both mated and virgin males were more likely to win when resident, but since mated residents may have experienced pheromone, but virgin residents did not, the lack of an interaction between the effects of male mating status and residency may in fact point to an asymmetrical effect of female pheromone on the aggression of mated and virgin males. There are also some observations wherein female presence has a differential effect on fighting intensity of unmated and mated S. longicaudum males (Kapranas \& Griffin n.d.). Such differential effects of female presence or pheromones may be related to the fact that $S$. longicaudum that have had no female presence are not immediately ready to mate (Ebssa et al. 2008).

Fatal fighting is expected to ensue whenever the value of the resource outbalances the risk of injury, as is the case of entomopathogenic nematode males who have to fight for access to females which are limited in space and time. Our study shows that competitor males adjust their fighting behaviour according to the objective (presence and quality of females) and subjective (male mating experience) components of resource value. Male mating 
experience could enhance the fighting ability (resource holding potential) but also its influence on fighting ability is confounded by resource value components.

\section{REFERENCES}

Abe, J., Kamimura, Y. \& Shimada, M. 2005. Individual sex ratios and offspring emergence patterns in a parasitoid wasp, Melittobia australica (Eulophidae), with superparasitism and lethal combat among sons. Behavioral Ecology and Sociobiology, 57, 366-373.

\section{Alsaiyah, M.A.M, Ebssa, L., Zenner A, O'Callaghan, K.M. \& Griffin, C.T. 2009. Sex} ratios and sex-biased infection behaviour in the entomopathogenic nematode genus Steinernema. International Journal for Parasitology, 39, 725-734.

Ancona, S., Drummond, H. \& Zaldivar-Rae, J. 2010. Male whiptail lizards adjust energetically costly mate guarding to male-male competition and female reproductive value. Animal Behaviour, 79, 75-82.

Andersson, M. 1994. Sexual selection. Princeton (NJ): Princeton University Press.

Anderson, C., Cremer, S. \& Heinze, J. 2003. Live and let die: why fighter males of the ant Cardiocondyla kill each other but tolerate their winged rivals. Behavioural Ecology, 14, 54-62.

Arnott, G. \& Elwood, R.W. 2008. Information gathering and decision making about resource value in animal contests. Animal Behaviour, 76, 529-542.

Arnott, G. \& Elwood, R.W. 2009. Assessment of fighting ability in animal contests. Animal Behaviour, 77, 991-1004.

Birkhead, T.R. \& Møller, A.P. 1998. Sperm Competition and Sexual Selection. Academic Press, London. Pp. 826. 
Briffa, M., Hardy, I.C.W., Gammell, M.P., Jennings, D.J., Clarke, D.D. \& Goubault, M. 2013 Analysis of animal contest data. In: Hardy ICW, Briffa M, editors. Animal contests Cambridge (UK): Cambridge University Press. p. 47-85.

Briffa, M. \& Lane, S.M. 2017. The role of skill in animal contests: a neglected component of fighting ability. Proceedings of the Royal Society B, 284, 20171596.

Briffa, M. \& Sneddon, L.U. 2007. Physiological constraints on contest behaviour. Functional Ecology, 21, 627-637.

Brown, W.D., Smith, A.T., Moskalik, B.\& Gabriel, J. 2006. Aggressive contests in house crickets: size, motivation and the information content of aggressive songs. Animal Behaviour, 72, 225-233.

Brown, W.D., Chimenti, A.J. \& Siebert, J.R. 2007. The payoff of fighting in house crickets: motivational asymmetry increases male aggression and mating success. Ethology, 113, 457-465.

Buena, L.J. \& Walker, S.E. 2008. Information asymmetry and aggressive behaviour in male house crickets, Acheta domesticus. Animal Behaviour, 75, 199-204.

Crespi, B.J. 1988. Risks and benefits of lethal male fighting in the colonial, polygynous thrips Hoplothrips karnyi (Insecta: Thysanoptera). Behavioral Ecology Sociobiology, 22, 293-301.

Cook, J.M. \& Bean, D. 2006. Cryptic male dimorphism and fighting in a fig wasp. Animal Behaviour, 71, 1095-1101.

Dick, J.T.A \& Elwood, R.W. 1990. Symmetrical assessment of female quality by male Gammarus pulex (amphipoda) during struggles over precopula females. Animal Behaviour, 40, 877-883.

Dillman, A.R. \& Sternberg, P.W. 2012. Quick guide: entomopathogenic nematodes. Current Biology, 22, 430-431. 
DeCarvalho, T.N., Watson P.J. \& Field SA. 2004. Costs increase as ritualized fighting progresses within and between phases in the sierra dome spider, Neriene litigiosa. Animal Behaviour, 68, 473-482.

Dugatkin, L.A. \& Dugatkin, A.D. 2011. Overestimating resource value and its effects on fighting decisions. PLoS ONE 6:e19924

Ebssa, L., Dix, I. \& Griffin, C.T. 2008. Female presence is required for male sexual maturity in the nematode Steinernema longicaudum. Current Biology, 18, R997-R998.

Enquist, M. \& Leimar, O. 1987. Evolution of fighting behavior-the effect of variation in resource value. Journal of Theoretical Biology, 127, 187-205.

Enquist, M. \& Leimar, O. 1990. The evolution of fatal fighting. Animal Behaviour, 39,1-9.

Hardy, I.C.W \& Brifa M. 2013. Animal contests. Cambridge (UK): Cambridge University Press.

Hamilton, W.D. 1979. Wingless and fighting males in fig wasps and other insects. In: Blum MS, Blum NA, editors. Sexual selection and reproductive competition in insects. London: Academic Press. p. 167-220.

Hartley, C.J. 2017. Pheromones in entomopathogenic nematodes: effects on dispersal and reproductive behaviours. $\mathrm{PhD}$ Thesis, Maynooth University.

Hoefler, C.D., Guhanarayan, G., Persons, M.H., Rypstra, A.L. 2009. The interaction of female condition and mating status on male-male aggression in a wolf spider. Ethology, 115, $331-338$.

Hsu, Y., Earley, R.L. \& Wolf, L.L. 2006. Modulation of aggressive behaviour by fighting experience: mechanisms and contest outcomes. Biological Reviews, 81, 33-74.

Innocent, T.M., West, S.A, Sanderson, J.L., Hyrkkanen, N. \& Reece, S.E. 2011. Lethal combat over limited resources: testing the importance of competitors and kin. Behavioural Ecology, 22, 923-931 
Innocent, T.M., Savage, J., West, S.A. \& Reece SE. 2007. Lethal combat and sex ratio evolution in a parasitoid wasp. Behavioural Ecology, 18, 709-715.

Jackson, R.R., Walker, M.W., Pollard, S.D. \& Cross, F.R. 2006. Influence of seeing a female on the male-male interactions of a jumping spider, Hypoblemum albovittatum. Journal of Ethology, 24, 231-238.

Judge, K.A, Ting, J.J., Schneider, J. \& Fitzpatrick, M.J. 2010. A lover, not a fighter: mating causes male crickets to lose fights. Behavioral Ecology and Sociobiology, 64, 1971-1979.

Kapranas, A \& Griffin, C.T. n.d. male-male fatal fights in groups of entomopathogenic nematodes: female presence modulates differentially fighting behaviour in mated and virgin males. Unpublished manuscript.

Kapranas, A., Maher, A.M.D. \& Griffin, C.T. 2016. Higher relatedness mitigates mortality in a nematode with lethal male fighting. Journal of Evolutionary Biology, 29, 344-351.

Kasumovic, M.M., Mason, A.C., Andrade, M.C.B. \& Elias, D.O. 2011. The relative importance of RHP and resource quality in contests with ownership asymmetries. Behavioral Ecology, 22, $39-45$

Kaya, H.K. \& Gaugler, R. 1993. Entomopathogenic nematodes. Annual Review of Entomology, 38, 181-206.

Kaya, H.K., \& Stock, S.P. 1997. Techniques in insect nematology. In Lacey, editor. Manual of Techniques in Insect Pathology. New York (USA), Academic Press, p. 281-324.

Kemp, D.J. 2006. Ageing, reproductive value, and the evolution of lifetime fighting behaviour. Biological Journal of the Linnean Society, 88, 565-578.

Keil, P.L \& Watson, P.J. 2010. Assessment of self, opponent and resource during male-male contests in the sierra dome spider, Neriene litigiosa: Linyphiidae. Animal Behaviour, 80, 809-820. 
Killian, K.A. \& Allen, J.R. 2008. Mating resets male cricket aggression. Journal of Insect Behaviour, 21, 535-548.

Kokko, H. 2013. Dyadic contests: modelling fights between two individuals. In: Hardy ICW, Briffa M, editors. Animal contests Cambridge (UK): Cambridge University Press. p. 532.

LaMunyon, C.W. \& Ward, S. 1995. Sperm precedence in a hermaphroditic nematode (Caenorhabditis elegans) is due to competitive superiority of male sperm. Experientia, $51,817-823$.

LaMunyon, C.W. \& Ward, S. 1999. Evolution of sperm size in nematodes: sperm competition favours larger sperm. Proceedings of the Royal Society B, 266, 263-267.

Lewis, E.E, Barbarosa, B. \& Gaugler, R. 2002. Mating and sexual communication by Steinernema carpocapsae (Nemata: Steinernematidae). Journal of Nematology, 34, $328-331$.

Liu, P.C., Wei, J.R., Tian, S. \& Hao, D.J. 2017. Male-male lethal combat in the quasigregarious parasitoid Anastatus disparis (Hymenoptera: Eupelmidae). Scientific Reports, 7, 11875.

Liu, P. \& Hao, D.J. 2019. Effect of variation in objective resource value on extreme male combat in a quasi-gregarious species, Anastatus disparis. BMC Ecology, 19, 21

Mariette, M.M., Cathaud, C., Chambon, R. \& Vignal, C. 2013. Juvenile social experience affects pairing success at adulthood: congruence with the loser effect? Proceedings of the Royal Society B, 280, 20131514.

Matthews, R.W., Gonzalez, J.M., Matthews, J.R. \& Deyrup LD. 2009. Biology of the parasitoid Melittobia (Hymenoptera: Eulophidae). Annual Review of Entomology, 54, 251-266.

Maynard Smith, J. \& Price, G.R. 1973. The logic of animal conflict. Nature, 246, 15-18. 
Maynard Smith, J. \& Parker, G.A. 1976. The logic of animal contests. Animal Behaviour, 24, 159-175.

Moya-Larano, J. \& Wise, D.H. 2000. Survival regression analysis: a powerful tool for evaluating fighting and assessment. Animal Behaviour, 60, 307-313.

Parker, GA. 1974. Assessment strategy and the evolution of fighting behaviour. Journal of Theoretical Biology, 47, 223-243.

Pérez-Staples, D., Martínez-Hernández, M.G. \& Aluja, M. 2010. Male age and experience increases mating success but not female fitness in the Mexican fruit fly. Ethology, 116, $778-786$.

Piper, W.H., Walcott, C., Mager, J.N. \& Spilker, F.J. 2008. Fatal battles in common loons: a preliminary analysis. Animal Behaviour, 75, $1109-1115$.

Poinar, G.O. 1990. Biology and taxonomy of Steinernematidae and Heterorhabditidae. in Gaugler R, Kaya HK editors. Entomopathogenic nematodes in biological control Boca Raton, FL, CRC Press: Pp. 23-62.

Rico-Guevara, A. \& Hurme, L. 2019. Intrasexually selected weapons. Biological Reviews, 94, 60-101.

Sato, Y., Egas, M. \& Sabelis, M.W. \& Mochizuki, A. 2013. Male-male aggression peaks at intermediate relatedness in a social spider mite. Ecology and Evolution, 3, 2661-2669.

Simmons, LW. 2001. Sperm Competition and Its Evolutionary Consequences in the Insects. Princeton Univ. Press, Princeton, NJ.

Smith, I.P., Huntingford, F.A., Atkinson, R.J.A. \& Taylor, A.C. 1994. Mate competition in the velvet swimming crab Necora puber: effects of perceived resource value on male agonistic behavior. Marine Biology, 120, 579-584. 
Sneddon, L.U., Huntingford, F.A., Taylor, A.C., \&Clare, A.S. 2003. Female sex pheromone-mediated effects on behavior and consequences of male competition in the shore crab (Carcinus maenas). Journal of Chemical Ecology, 29, 55-70.

Stockermans, B.C. \& Hardy, I.C.W. 2013. Subjective and objective components of resource value additively increase aggression in parasitoid contests. Biology Letters, 9, 20130391

Ward, S. \& Carrel, J.S. 1979. Fertilization and sperm competition in the nematode Caenorhabditis elegans. Developmental Biology, 73, 304-321

Wells, M.S. 1988. Effects of body size and resource value on fighting behaviour in a jumping spider. Animal Behaviour, 36, 321-326.

Yasuda, C.I., Matsuo, K., Wada, S. 2015. Previous mating experience increases fighting success during male-male contests in the hermit crab Pagurus nigrofascia. Behavioral Ecology and Sociobiology, 69, 1287-1292.

Zenner, A.N.R.L, O'Callaghan, K.M., Griffin, C.T. 2014. Lethal fighting in nematodes is dependent on developmental pathway: male-male fighting in the entomopathogenic nematode Steinernema longicaudum. PLoS One, 9, e89385.

Zhang, S., Ai, H. \& Li, D. 2019. Mating changes a male contestant from a loser to a winner in male-male competition in a wolf spider. Biological Journal of the Linnean. Society, $128,83-92$ 
473 Figure 1 Fights between two mated males, in the presence or absence of a female within 30

474

475

476

477

478

479

480

481

482

483

484

485

486

487

488

489

490

491

492

493

494

495 86

minutes. Bars show average values with asymmetrical, poisson-distributed errors. Bars with accompanied by the same letter are not significantly different (post-hoc multiple comparison tests with Bonferroni adjustment, $\alpha=0.05$ ).

Figure 2. Latency to first fight between two mated males in the presence or absence of a female within 30 minutes.

Figure 3. Time spent fighting by two males in the presence or absence of a female within 30 minutes. Data are represented as box and whisker plots with median (horizontal line), 25-75 percentiles (boxes), ranges for the bottom $25 \%$ and the top $25 \%$ of the data values (whiskers).

Figure 4. Probability of winning of mated and virgin males in pairs of one mated and one virgin adult male set up either in the drop in which mated male had been reared and mated or in the drop in which the unmated male had been reared. Bars show estimated average values with asymmetrical, binomially distributed standard errors .

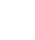


496

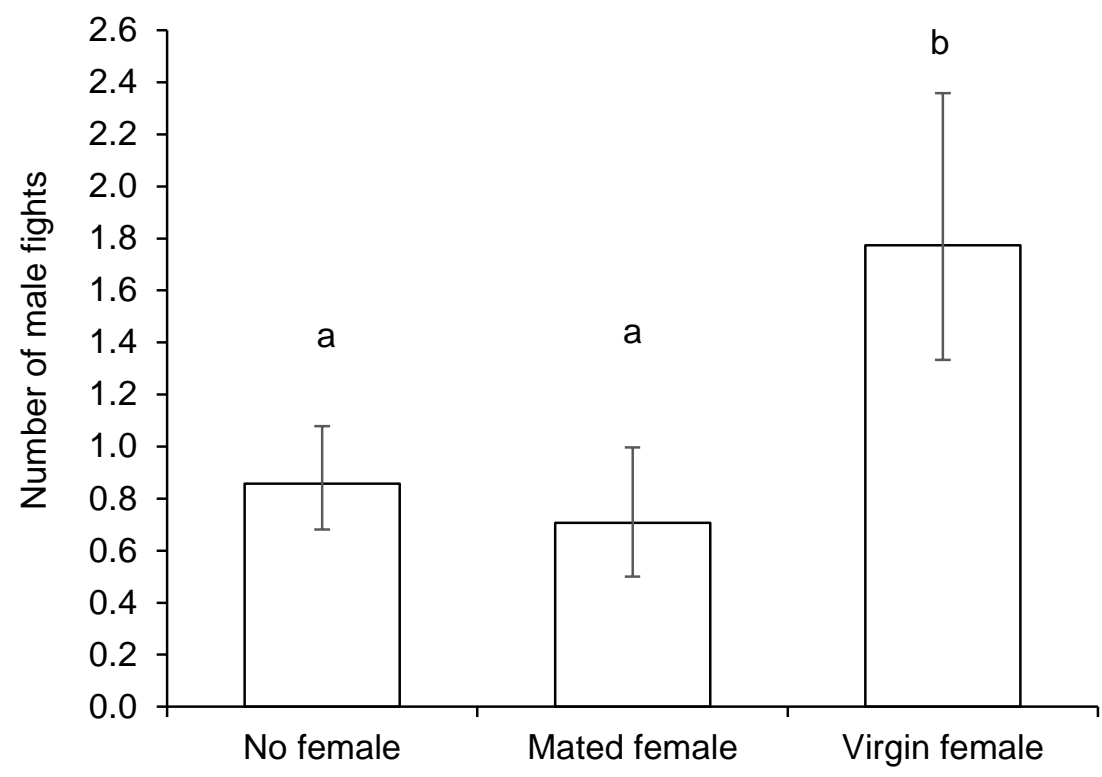

497

498

499

500

501

502 


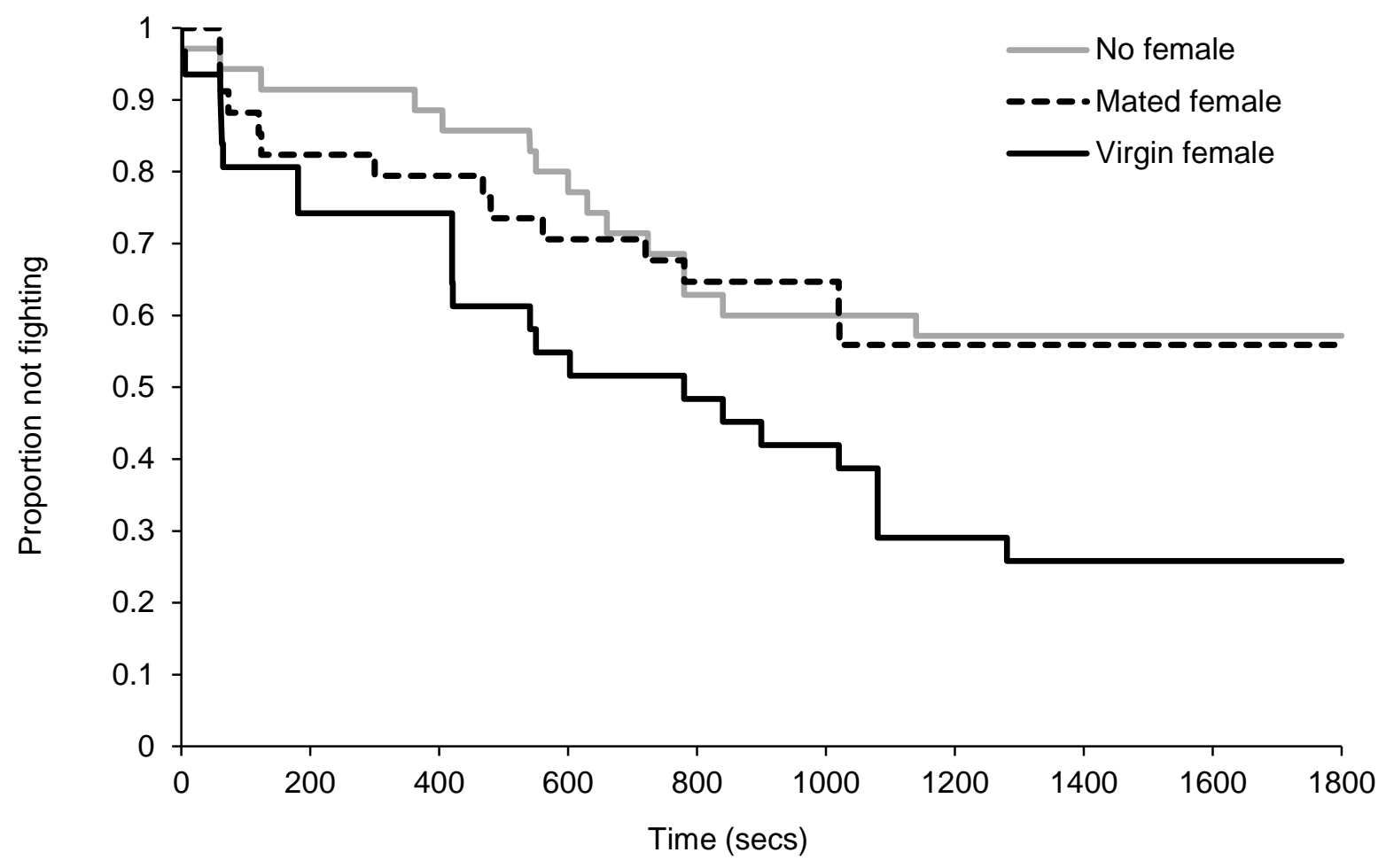

504

505

506

507

508

509 


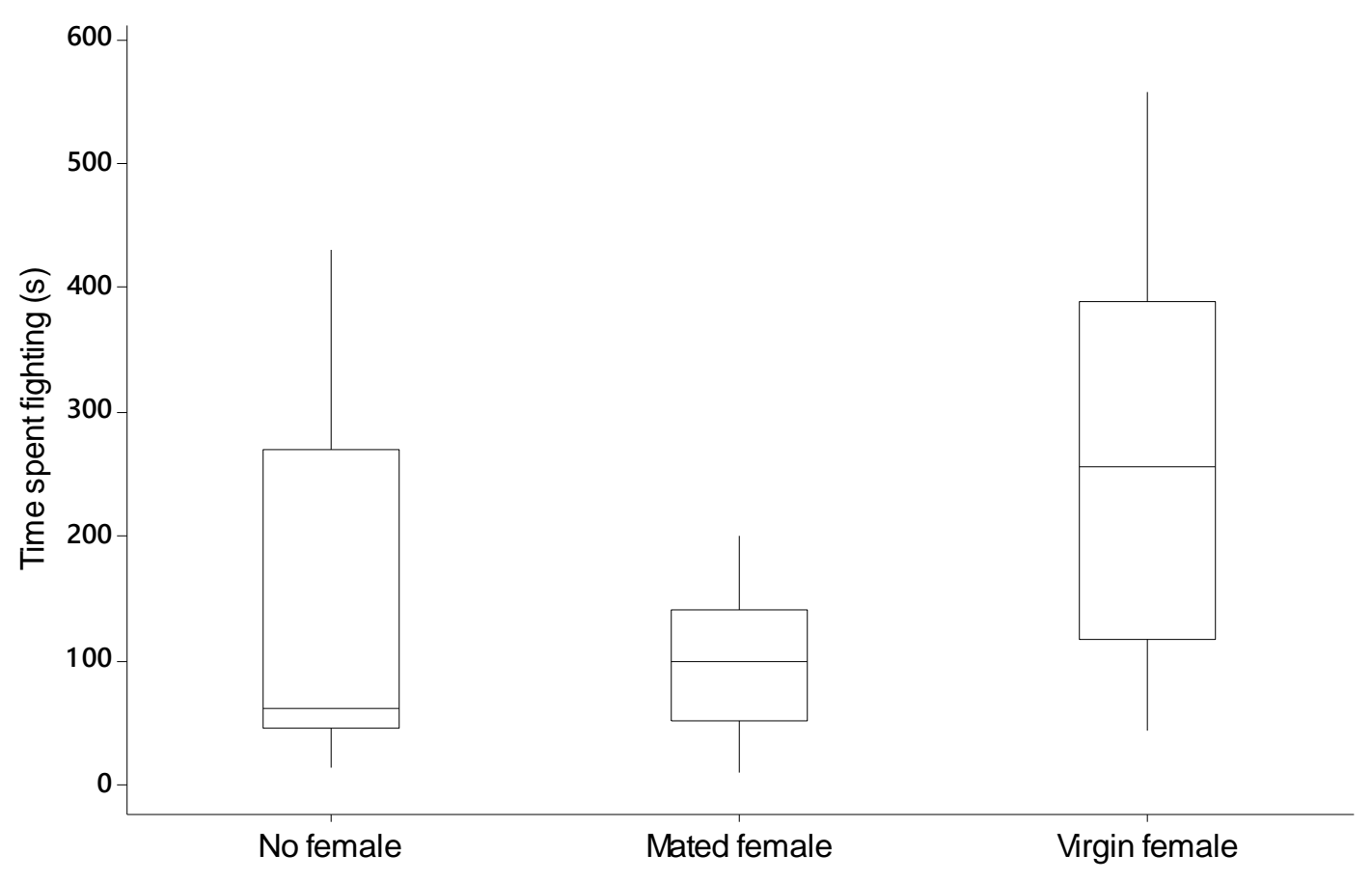

510

511

512

513

514

515

516

517

518

519

520

521

522

523

524

525 


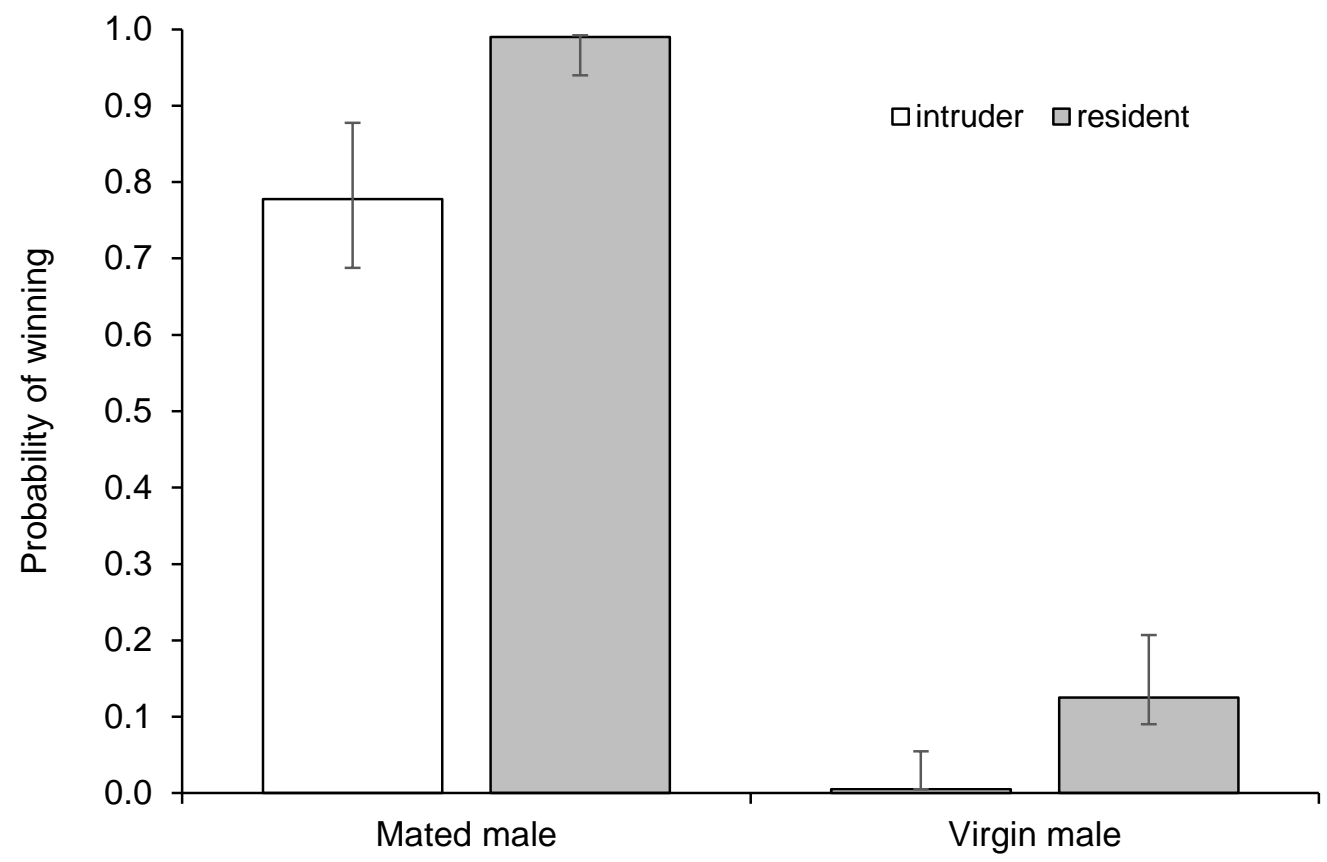




\section{Animal Behaviour [ANBEH-D-19-00856] - ACKNOWLEDGEMENTS}

\section{ACKNOWLEDGEMENTS}

We thank Ms Aideen Byrne for technical assistance. All experimentation reported in this work abides to the principles of replacement, reduction and refinement as endorsed by the Association for the Study of Animal Behaviour (ASAB).

\section{FUNDING}

This work was supported by Science Foundation Ireland (Grant number RFP05/EEB0009) and the EU Seventh Framework Programme (grant agreement nº 612713 BIOCOMES Project). 


\section{ANIMAL WELFARE NOTE: Objective and subjective components of resource value in lethal fights between male entomopathogenic nematodes}

The experiments reported in this paper were conducted with invertebrates - insects and nematodes - from laboratory cultures. The experiments were conducted in accordance to Science Foundation Ireland's policy concerning use of animals in research (outlined in Directive 2010/63/EU) and is implemented by the Health Products Regulatory Authority (HPRA), the competent authority in Ireland responsible for the protection of animals used for scientific purposes. All experimentation reported in this work abides to the principles of replacement, reduction and refinement as endorsed by the Association for the Study of Animal Behaviour (ASAB). 